\title{
Four chemical elements added to periodic table
}

\section{Elements 113, 115, 117 and 118 to be named by scientists from Russia, the United States and Japan.}

\section{Richard Van Noorden}

04 January 2016

TREND WATCH: Four new elements have been officially added to the periodic table, completing its seventh row.

Elements 113, 115, 117 and 118 have been pencilled in on the table for years, and laboratories in Russia, the United States and Japan have made multiple claims to have discovered them. But official recognition had to wait until the end of 2015, when a group of independent experts agreed that the evidence was valid (see chart). The International Union of Pure and Applied Chemistry (IUPAC), headquartered in Research Triangle Park, North Carolina, announced the group's conclusions on 30 December.

\section{FOUR NEW CHEMICAL ELEMENTS CONFIRMED}

\section{Elements $113,115,117$ and 118 complete the seventh row} of the periodic table.

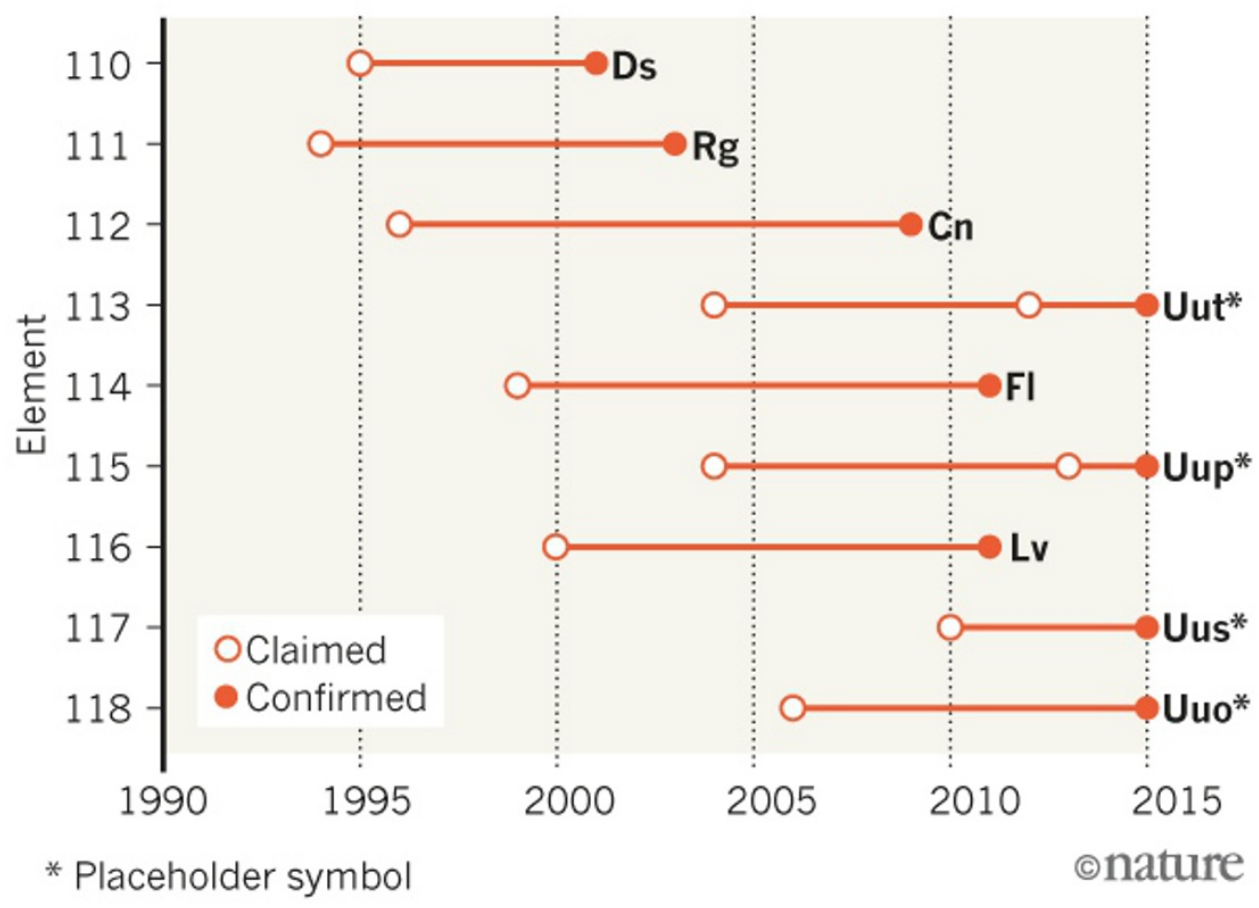

All of the elements were created in the lab, by smashing lighter atomic nuclei together. The unstable agglomerations of protons and neutrons last mere fractions of a second before they fall apart into smaller, more stable fragments.

The teams that have been given credit for the discoveries can now put forward proposals for the elements' names and two-letter symbols. Elements can be named after one of their chemical or physical properties, a mythological concept, a mineral, a place or country, or a scientist.

Priority for discovering element 113 went to researchers in Japan, who are particularly delighted because it will become the first artificial element to be named in East Asia. When the element was first sighted 12 years ago, 'Japonium' was suggested as a name. 


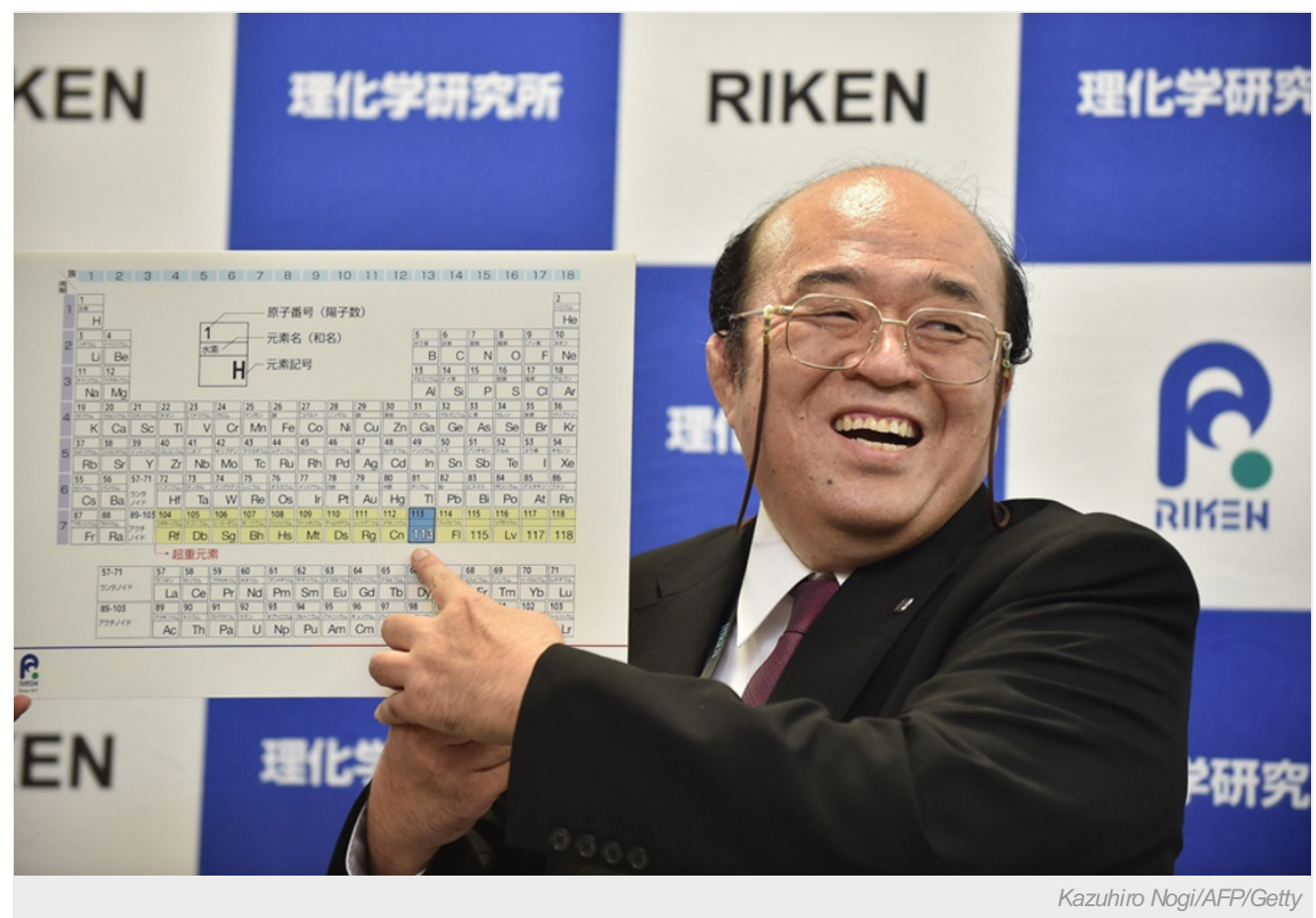

Japanese chemist Kosuke Morita is part of a team that has been given credit for discovering element 113.

The team at the RIKEN Nishina Center for Accelerator-based Science in Wako, near Tokyo, made its first claim to have spotted element 113 in 2004, and followed it up with a more convincing sighting in 2012. By then, it had created three atoms of the element. "To scientists, this is of greater value than an Olympic gold medal," said Ryoji Noyori, who received the 2001 Nobel Prize in Chemistry, at a press conference about the IUPAC decision. (Noyori was not a member of the Japanese team, but is a former president of RIKEN).

Russian and US researchers made a rival claim to have discovered 113, but were not given priority by the expert group, drawn from IUPAC and the International Union of Pure and Applied Physics (IUPAP).

However, Russia and the United States did get the credit and naming rights for the other new elements. Elements 115 and 117 were first created by a collaboration between the Joint Institute for Nuclear Research in Dubna, Russia, the Lawrence Livermore National Laboratory in Livermore, California, and the Oak Ridge National Laboratory in Tennessee, the IUPAC/IUPAP committee said. Work from other teams, such as a Swedish group using a German accelerator, helped to confirm element 115's existence.

The credit for discovering element 118 — the heaviest ever created — has been assigned to the Dubna and Lawrence Livermore teams. The element has a chequered history: a 1999 claim to have made it was retracted two years later amid accusations that data had been falsified.

Physicists will now try to create elements 119 and 120, a feat that should be possible with current technology, says Rolf-Dietmar Herzberg, a nuclear physicist at the University of Liverpool, UK. No one has yet claimed a sighting, however: researchers at the GSI Helmholtz Centre for Heavy lon Research in Darmstadt, Germany, tried for five months in 2012 without success. Beyond element 120 , researchers agree, the chances of getting two nuclei to fuse are vanishingly small.

Nature | doi:10.1038/nature.2016.19112 